NISTIR 6565

\title{
Tensile Strength of an Interlocking Composite Connection
}

\section{Dat Duthinh}

October 2000

Structures Division

Building and Fire Research Laboratory

Gaithersburg, Maryland 20899

\section{NLT}

United states Department of Commerce Technology Administration National Institute of Standards and Technology

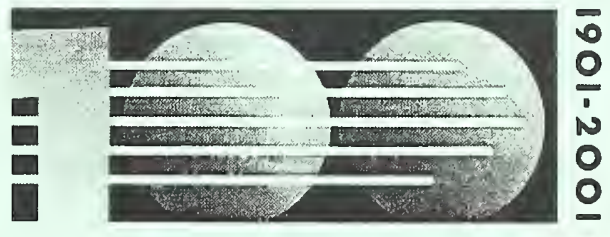

QC

100

.456

N0.6565

$2000 \quad 6.2$ 
NISTIR 6565

\section{Tensile Strength of an Interlocking Composite Connection}

\section{Dat Duthinh}

October 2000

Structures Division

Building and Fire Research Laboratory

National Institute of Standards and Technology

Gaithersburg, MD 20899

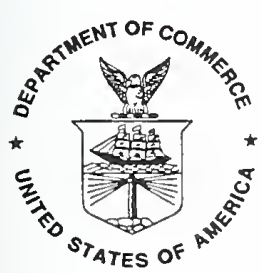

U.S. Department of Commerce

Norman Y. Mineta, Secretary

Technology Administration

Dr. Cheryl L. Shavers, Under Secretary of Commerce for Technology National institute of Standards and Technology Raymond G. Kammer, Director 



\begin{abstract}
Twenty four tests of an interlocking fiber-reinforced polymer (FRP) connection show that, although the connection is much weaker than the theoretical strength of the panel under the same type of load (in-plane tension transverse to the main reinforcement direction), it is well designed and performs its function satisfactorily. The tensile strength of the connection exhibits the least variability in the interlocked, no bond configuration. Adhesive bonding adds significantly to the strength of this interlocking joint. Spreading adhesive on both mating faces in the absence of an interlocking toggle produces a more complete bond area and a thicker bond line, resulting in significantly higher connection strength than if the adhesive is deposited on only one face and a toggle is used. Infills of various stiffness have no effect on strength and the toggle shows no sign of damage at connection failure.
\end{abstract}

Keywords: adhesive, bond, composite, connection, fiber-reinforced polymer, FRP, interlocking, joint, panel, tensile strength. 


\section{ACKNOWLEDGMENT}

This study was made possible by a grant from the Advanced Technology Program of NIST (Felix Wu, Program Manager, Composite Materials). Strongwell (Bristol, VA) provided test samples, Maunsell (Beckenham, UK) technical data and Ashland Chemicals (Columbus, OH) the adhesive and applicator. Frank Davis and Mark Kile assisted with the experiments, Nicholas Carino with the data analysis, Fahim Sadek and Monica Starnes with the graphics. To all, the author is grateful.

\section{DISCLAIMER}

Certain trade names and company products are mentioned in the text or identified in an illustration in order to adequately specify the experimental procedure and equipment used. In no case does such an identification imply recommendation or endorsement by the National Institute of Standards and Technology, nor does it imply that the products are necessarily the best available for the purpose. 


\section{Contents}

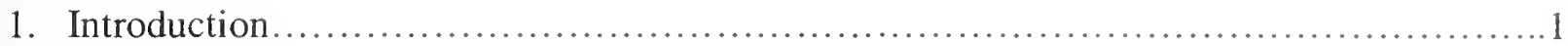

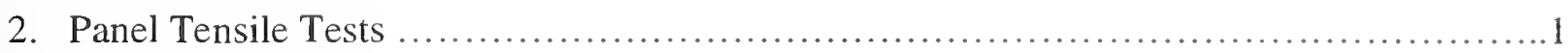

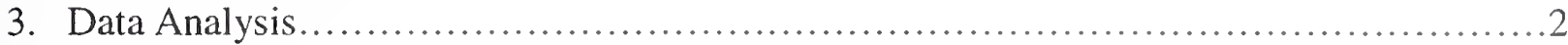

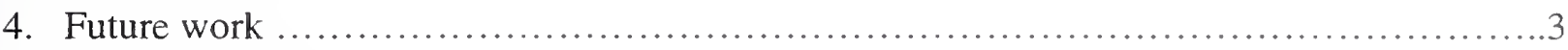

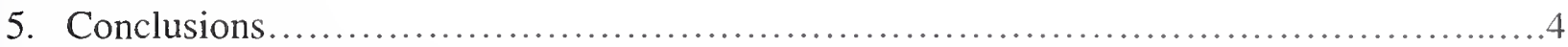

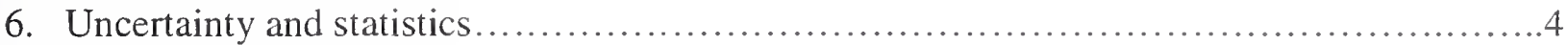

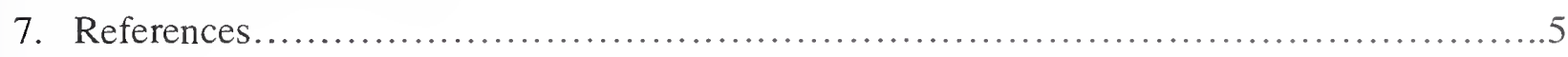




\section{Tensile Strength of an \\ Interlocking Composite Connection}

\section{Introduction}

FRP (fiber-reinforced polymer) structural members are increasingly used in civil engineering applications, such as in bridge decks and girders. One promising application is in residential housing, where FRP panels can be assembled quickly on site, without the need for additional framing. The speed of erection is particularly important for emergency and military shelters. Further advantages are the light weight of the material and the possibility of fabricating standardized panels and connections in the factory, thus potentially leading to lower cost and improved quality control.

This work evaluates the tensile strength of a particular type of interlocking joint used to assemble double-skinned panels (Fig. 1). The panels can be used in walls, floors and roofs of shelters and are assembled by driving a toggle into the jaws of the end cells (Head and Churchman, 1989). Foam can be injected into the cells formed by the panel skins and stiffeners for insulation. For permanent structures, adhesive bonding can also be used in addition to mechanical interlocking. If no adhesive is used, disassembly and reuse are possible.

Several interlocking composite joints are commercially available (Duthinh, 2000). However, they all are proprietary designs and their performance is not generally known to the engineering community. To facilitate the use of this promising technology, NIST is undertaking a series of tests to measure the performance of this type of joint and to make the results available in the public domain. It is our hope that more companies will participate in this program, which, in conformance with NIST mission, aims to serve the public and the industry.

\section{Panel Tensile Tests}

Under wind or earthquake loads, the external walls and internal partitions of a house can act as shear walls, i.e., they resist in-plane, biaxial, diagonal tension and compression. Crucial to this function is the performance under tension of the connections between the wall panels. For this purpose, we tested 24 specimens $152 \mathrm{~mm}$ (6 in) wide in tension (Width is the dimension perpendicular to the plane of Fig. 4. See Tables $1 \mathrm{~m}$ for SI units and 1 for US customary units). Of these, 13 experiments tested the connection in a "single" configuration, and 11 in a "double" configuration.

The "single" configuration, shown in Fig. 2, was intended to measure the effect of various infills on the performance of the connection. Infills of various stiffness, such as foam, high-strength mortar, or air (no infill), could affect the resistance of the cell to gross distortion, thus influencing the tendency for the connection to disengage and fail. Two cells, including one end cell, were attached to a steel fixture by the FRP toggle. The steel fixture was custom-made to exactly conform to the toggle. The lower cell had a thin aluminum liner that served to spread the load and minimize stress concentration and distortion of the cell. Tension was applied via a thick steel plate inserted into the lower cell and its liner and bolted at its ends to a fixture attached to the testing machine. The stiff steel plate ensured a fairly uniform load distribution 
over the length of the cell (or width of the specimen). This set-up worked well and failure always occurred at the FRP connection. The aluminum liner thus prevented possible premature failure due to load application.

Figure 3 shows a "single" test with foam infill. Note the delamination cracks due to radial normal tension caused by straightening out of the right lip. (Lips refer to the cantilevered parts of the panel in contact with the toggle, whereas jaws refer to the entire face of the end cell).

The "double" tests were intended to measure the performance of the connection in the configuration used in practice. The set-up (Fig. 4) involved two upper cells and an upper load fixture that were the mirror image of the (lower) cells and load fixture shown in Figs. 2 and 3. Three possible configurations were tested: interlock only, adhesive bond only, and both interlock and bond. Figs. 5 and 6 show details of the "double" tests, where cracks are typical of the failures observed. All panel tensile tests were conducted at a loading rate of $0.76 \mathrm{~mm} / \mathrm{min}(0.03$ $\mathrm{in} / \mathrm{min}$ ).

For the interlocked and bonded specimens, we followed the manufacturer's bonding recommendations: First, we lightly sanded and wiped the mating surfaces clean. Next, we applied to only one of the two pieces to be joined a $3 \mathrm{~mm}$ (1/8 in) diameter bead of adhesive in each of two grooves on the sides of the toggle cavity. We then aligned and mated the two parts together and inserted the toggle, making sure that no adhesive was applied to the toggle or toggle cavity. The specimen was left undisturbed to cure for at least 16 hours. For the bonded only specimens, the procedure was similar, except that adhesive was applied to both mating surfaces, which were subsequently clamped together.

\section{Data analysis}

\section{"Single" tests}

For the $n=13$ "single" tests, results for the $152 \mathrm{~mm}(6 \mathrm{in})$ specimens are as follows:

- Mean strength: $1.70 \mathrm{kN}$ (381 lbf)

- Standard deviation: $\sigma=207$ N (45 lbf)

- Standard error: $\sigma / \sqrt{n}=57.4 \mathrm{~N}(12.4 \mathrm{lbf})$

- Insert (air, foam or mortar) has no significant effect (Fig. 7, and Section 6, Note 3).

\section{"Double" tests}

The "double" tests showed that the tensile strengths corresponding to bond only, interlock only, or both interlock and bond were significantly different (Fig. 8, and Section 6, Notes 3 and 4). In addition, the load deflection curves showed clearly a decrease in stiffness when the applied tension overcame the preload exerted by the toggle and the jaws separate (Tables $1 \mathrm{~m}, 1$ and Fig. $10 \mathrm{~m}, 10)$. This change in stiffness thus provided a means to measure the preload. For the three interlocked only specimens (\#25-27), the mean preload exerted by the toggle was $633 \mathrm{~N}$ (142 lbf). Compared to the "single" tests (Figs. 9m, 9), the interlocked only, "double" tests exhibited a surprisingly lower mean strength and small spread (tests 25-27 have a mean strength of $1.39 \mathrm{kN}$ 
or $312 \mathrm{lbf}$ and a standard deviation of $40 \mathrm{~N}$ or $9.0 \mathrm{lbf}$ ). Once of the jaws have separated, we expected the "double" tests to show the same behavior and ultimate strength as the "single" tests.

Connections that were both bonded and interlocked exhibited a surprisingly lower strength (mean $4.42 \mathrm{kN}$ or $994 \mathrm{lbf}$ of tests 22-24) than those that were bonded only (mean $8.68 \mathrm{kN}$ or $1950 \mathrm{lbf}$ of tests 29-31). As mentioned above, the bonded only specimens had adhesive spread on both mating faces, whereas the bonded and interlocked specimens had adhesive spread on one face only. Also, the preload exerted by the toggle squeezed out all but a thin layer of adhesive, whereas in the bonded only cases, clamping was weaker, resulting in a thicker bond line. All the bonded only specimens $(\# 29,30,31)$ achieved $100 \%$ adhesive coverage of the jaw area. Connection failure occurred by tension failure of the FRP jaws near their surface, leaving a dull, fibrous surface, and not in the adhesive or at the adhesive-FRP interface. Only one of the interlocked and bonded specimens (\#32) had similar adhesive coverage and FRP failure, and it achieved a strength comparable to that of the bonded only specimen. The others ( $\# 22,23,24,28)$ had adhesive coverage ranging from $50 \%$ to $80 \%$ and failure included regions of adhesive-FRP interface failure, adhesive through-thickness failure as well as FRP near surface tensile failure. Bond failure for specimen 28, for example, was by FRP near surface tensile failure over $90 \%$ of the bonded area. However, this bonded area only covered $60 \%$ of the jaw surface, and caused a reduction in strength of $60 \%$ compared with specimen 32.

It is noteworthy that failure of the bonded specimens (Figs. $11 \mathrm{~m}$ and 11) was not necessarily more brittle than that of interlocked (Figs. $10 \mathrm{~m}$ and 10) or interlocked and bonded specimens (Figs.12m and 12). Bonded only specimens did not fail abruptly after the first peak load, but sometimes achieved a second peak of about the same magnitude after considerable deformation due mostly to gross distortion of the cells rather than strain in the adhesive (Figs. $11 \mathrm{~m}$ and 11).

\section{Coupon tests}

Four longitudinal coupons ( $305 \mathrm{~mm} \times 33 \mathrm{~mm}$ or $12 \mathrm{in} \times 1.3 \mathrm{in}$ ) and seven transverse coupons $(70 \mathrm{~mm} \times 14 \mathrm{~mm}$ or $2.75 \mathrm{in} \times 0.57 \mathrm{in})$ cut from the panel walls were tested in tension. The coupon ends and gage length were of the same width, and the ends were of triple thickness, bonded with the adhesive recommended by the manufacturer. The mean strengths measured were about $1 \sigma$ (one standard deviation) lower for transverse strength and $1.5 \sigma$ lower for longitudinal strength than the manufacturer's values (Tables 2 and 3). The slightly lower strength than the specified values should not be a cause for alarm as these tests were not standard ASTM tests, but rather were intended to be rapid tests to verify that the material was indeed what it was supposed to be.

\section{Future work}

Future tests will include in-plane and out-of plane shear and bending. Compression tests are not planned, because compression should not be a problem for this particular connection, as global buckling of the panel or local buckling of its walls would occur before gross distortion of the jaws due to compression. 


\section{Conclusions}

The tensile strength of the toggle connection exhibited the least variability in the interlocked only, "double" configuration. Adhesive bonding added significantly to the strength of this interlocking joint. Spreading adhesive on both mating faces in the absence of a toggle produced a more complete bond area and a thicker bond line, resulting in significantly higher connection strength than if the adhesive was deposited on only one face and a toggle was used. Infills of various stiffnesses had no effect on strength and the toggle showed no sign of damage at connection failure. Although the toggle connection is much weaker than the theoretical strength of the panel under the same type of load (in-plane tension transverse to the main reinforcement direction), it is well designed and performs its function satisfactorily.

\section{Uncertainty and statistics:}

Note 1, load uncertainty: According to the latest calibration sheet of the testing machine, for the relevant range of loads, $1070 \mathrm{~N}$ to $10700 \mathrm{~N}$ (240 lbf to $2400 \mathrm{lbf}$ ), the load displayed by the testing machine is less than $0.3 \%$ lower than the calibrating device. The maximum load was recorded directly by the testing machine, whereas other peak loads were read at a scanning rate of $10 \mathrm{~Hz}$. The scanned maximum load was less than $18 \mathrm{~N}$ (4 lbf) lower than the machine load.

With one exception, the widths of the specimens were within $1.6 \mathrm{~mm}(1 / 16 \mathrm{in})$ or $1 \%$ of the intended width of $152 \mathrm{~mm}$ (6 in). The exception was specimen 28, which had a width of $149 \mathrm{~mm}$ ( $57 / 8$ in). Results of test 28 were multiplied by $152 / 149=1.02$ for consistency with the other tests. Cumulative uncertainty for load per unit width is therefore estimated to be about $1.5 \%$.

Note 2, displacement uncertainty: Observations about stiffness and ductility relied on displacements, which were measured directly by the loading machine to control its loading rate. These measures were usually not precise enough for small displacements that occurred in coupon tests for example, but were adequate for large displacements caused by gross distortion of the cross-section, as occurred here. Nevertheless, observations based on displacements should only be used for comparison of similar test configurations and not in an absolute sense.

Note 3, F-test: Figures 7 and 8 are one-way, unbalanced ANOVA (analysis of variance) tables. Let $y_{i j}$ be the measured connection strength, where subscript $i$ denotes the test configuration, $j$ the test replication number, $n_{i}$ the total number of replicates per configuration, $I$ the total number of test configurations and $N$ the total number of tests. The components of variance are as follows:

$\begin{array}{lcl}\begin{array}{l}\text { Source } \\ \text { Mean }\end{array} & \begin{array}{c}\text { Degrees of freedom } \\ \text { Effect (Columns) }\end{array} & \text { Sum of squares } \\ \text { Error } & I-1 & N \bar{y}^{2} \\ & N-I & \sum_{i=1}^{I} n_{i}\left(\bar{y}_{i}-\bar{y}\right)^{2} \\ \text { Total } & \sum_{i=1}^{l} \sum_{j=1}^{n_{i}}\left(y_{i j}-\bar{y}_{i}\right)^{2} \\ & N & \sum_{i=1}^{I} \sum_{j=1}^{n_{i}} y_{i j}{ }^{2}\end{array}$


The mean square (MS) is the ratio of the sum of squares over the corresponding number of degrees of freedom. The $F$-test (likelihood ratio) for the effect is the ratio:

$$
\frac{\text { mean square for the deviations among the groups MS (effect) }}{\text { mean square for the deviations within the groups MS (error) }}
$$

The further the effects are from zero, the further the $F$-statistic is from one. This is measured by the probability that the value of $F_{(I-1) ;(N-I)}$ is greater than the ratio defined above.

Note 4, $t$ test: In Fig. 8, the averages of the connection strength for various configurations are also compared. Let $x_{i}$ and $y_{i}$ be the measurements, repeated $n$ and $k$ times respectively, for two configurations. We are interested in knowing if the difference in the means, $m_{x}-m_{y}$, estimated by the differences in the averages $\bar{x}-\bar{y}$ would be zero. If $s_{x}{ }^{2}$ and $s_{y}{ }^{2}$ denote the unbiased estimates of variance for $x_{i}$ and $y_{i}$, then a pooled estimate of variance can be defined:

$$
s_{p}^{2}=\frac{(n-1) s_{x}^{2}+(k-1) s_{y}^{2}}{n+k-2}
$$

The quantity $t=\frac{(\bar{x}-\bar{y})-0}{\sqrt{\frac{n+k}{n k}} s_{p}}$ is distributed as Student's $t$ with the number of degrees of freedom $v=n+k-2$. The table gives the probability that $m_{x}=m_{y}$.

\section{References}

Duthinh, D. (2000), "Connections of Fiber-Reinforced Polymer (FRP) Structural Members: a Review of the State of the Art," NISTIR 6532, NIST, Gaithersburg, MD.

Head, P.R. and Churchman, Q.E. (1989), "Design, Specification and Manufacture of a Pultruded Composite Construction System." Proc., BPF Symposium on Mass Production Composites, Imperial College, London, Sep., pp. 117-162. 


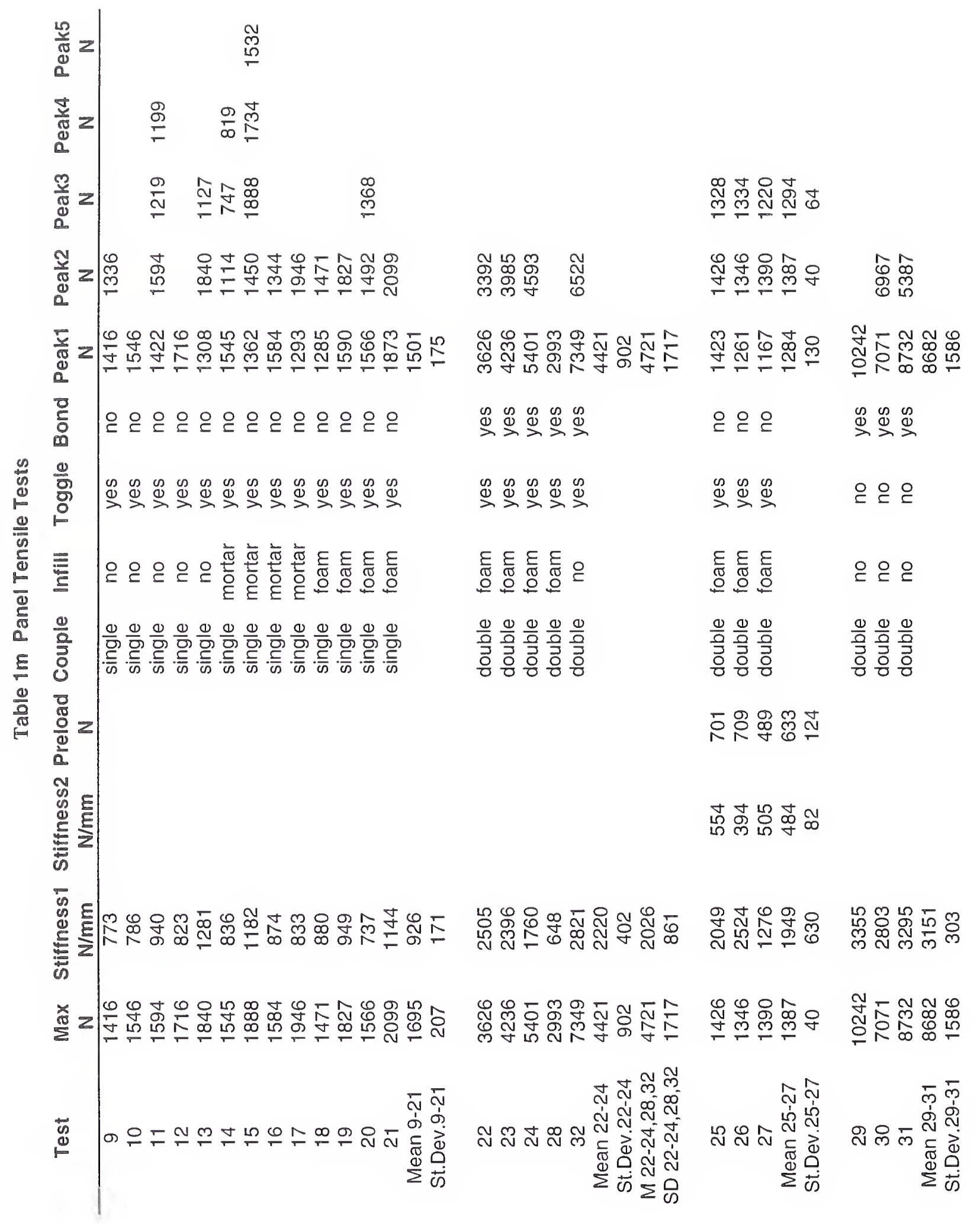




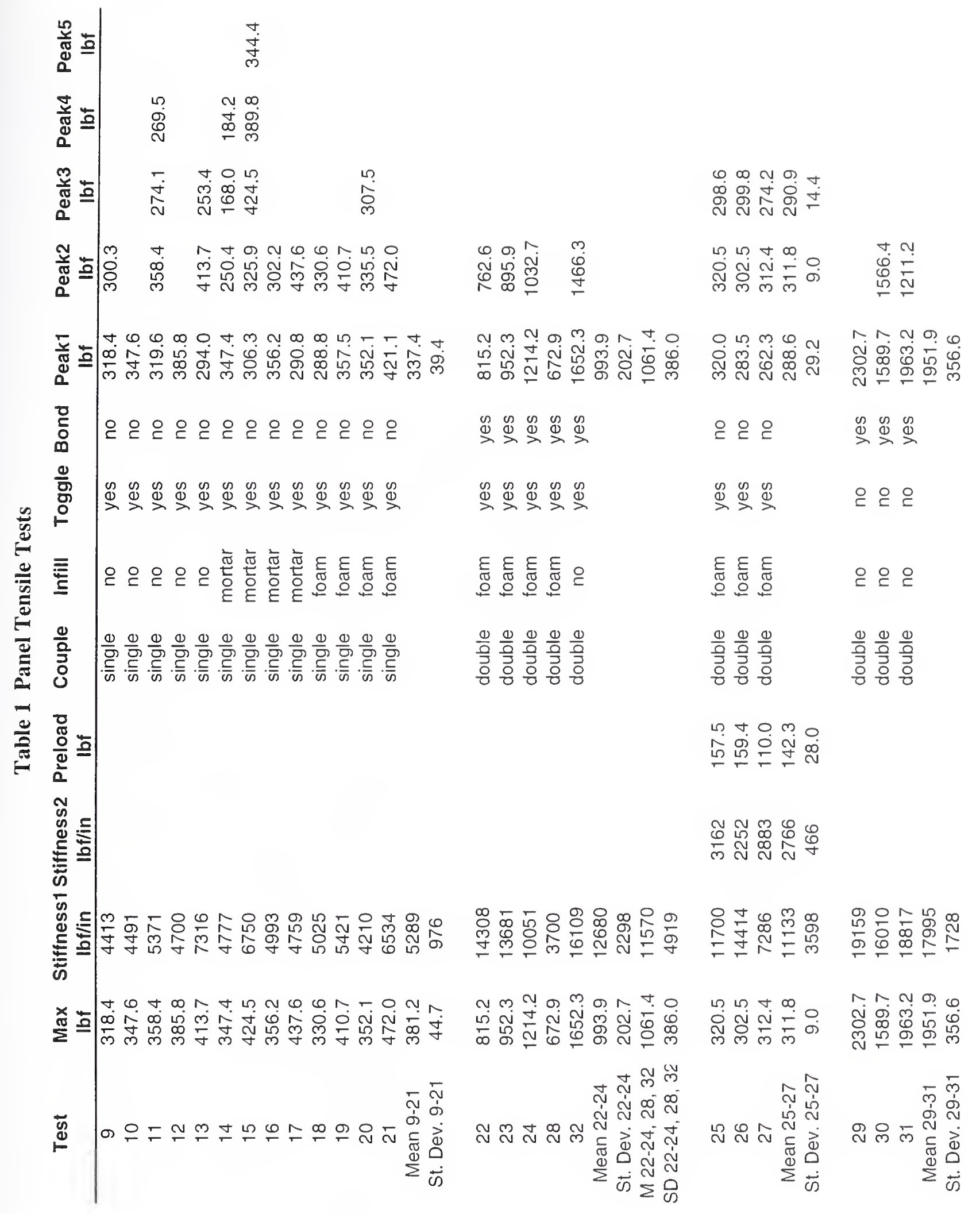


Table 2 Longitudinal Coupon Tests

\begin{tabular}{|c|c|c|c|c|c|c|c|c|}
\hline Test & \multicolumn{2}{|c|}{ Length } & \multicolumn{2}{c|}{ Width } & \multicolumn{2}{c|}{ Thickness } & \multicolumn{2}{c|}{ Strength } \\
\hline & $\mathrm{mm}$ & $\mathrm{in}$ & $\mathrm{mm}$ & $\mathrm{in}$ & $\mathrm{mm}$ & in & MPa & ksi \\
\hline 48 & 171 & 6.75 & 34.7 & 1.365 & 3.05 & 0.120 & 525.3 & 76.18 \\
\hline 59 & 171 & 6.75 & 33.9 & 1.334 & 2.79 & 0.110 & 524.4 & 76.05 \\
\hline 51 & 171 & 6.75 & 33.9 & 1.333 & 2.79 & 0.110 & 522.9 & 75.84 \\
\hline Mean & & & & & & & 532.1 & 77.17 \\
\hline St. dev. & & & & & & & 15.8 & 2.29 \\
\hline Manuf. Specs & & & & & & & 556 & 80.6 \\
\hline
\end{tabular}

Table 3 Transverse Coupon Tests

\begin{tabular}{|c|c|c|c|c|c|c|c|c|}
\hline Test & \multicolumn{2}{|c|}{ Length } & \multicolumn{2}{c|}{ Width } & \multicolumn{2}{c|}{ Thickmess } & \multicolumn{2}{c|}{ Strength } \\
\hline & $\mathrm{mm}$ & in & $\mathrm{mm}$ & in & $\mathrm{mm}$ & in & $\mathbf{M P a}$ & ksi \\
\hline 41 & 44.5 & 1.75 & 14.9 & 0.587 & 3.00 & 0.118 & 62.9 & 9.12 \\
\hline 42 & 44.5 & 1.75 & 14.9 & 0.587 & 3.00 & 0.118 & 59.2 & 8.58 \\
\hline 43 & 44.5 & 1.75 & 14.1 & 0.555 & 2.97 & 0.117 & 42.9 & 6.22 \\
\hline 45 & 44.5 & 1.75 & 13.7 & 0.538 & 3.00 & 0.118 & 54.1 & 7.84 \\
\hline 46 & 44.5 & 1.75 & 14.6 & 0.575 & 3.00 & 0.118 & 47.3 & 6.86 \\
\hline 47 & 44.5 & 1.75 & 14.1 & 0.554 & 3.00 & 0.117 & 53.4 & 7.74 \\
\hline Mean & & & & & & & 52.9 & 7.67 \\
\hline St. dev. & & & & & & & 6.3 & 0.91 \\
\hline Manuf. Specs & & & & & & & 58.5 & 8.48 \\
\hline
\end{tabular}




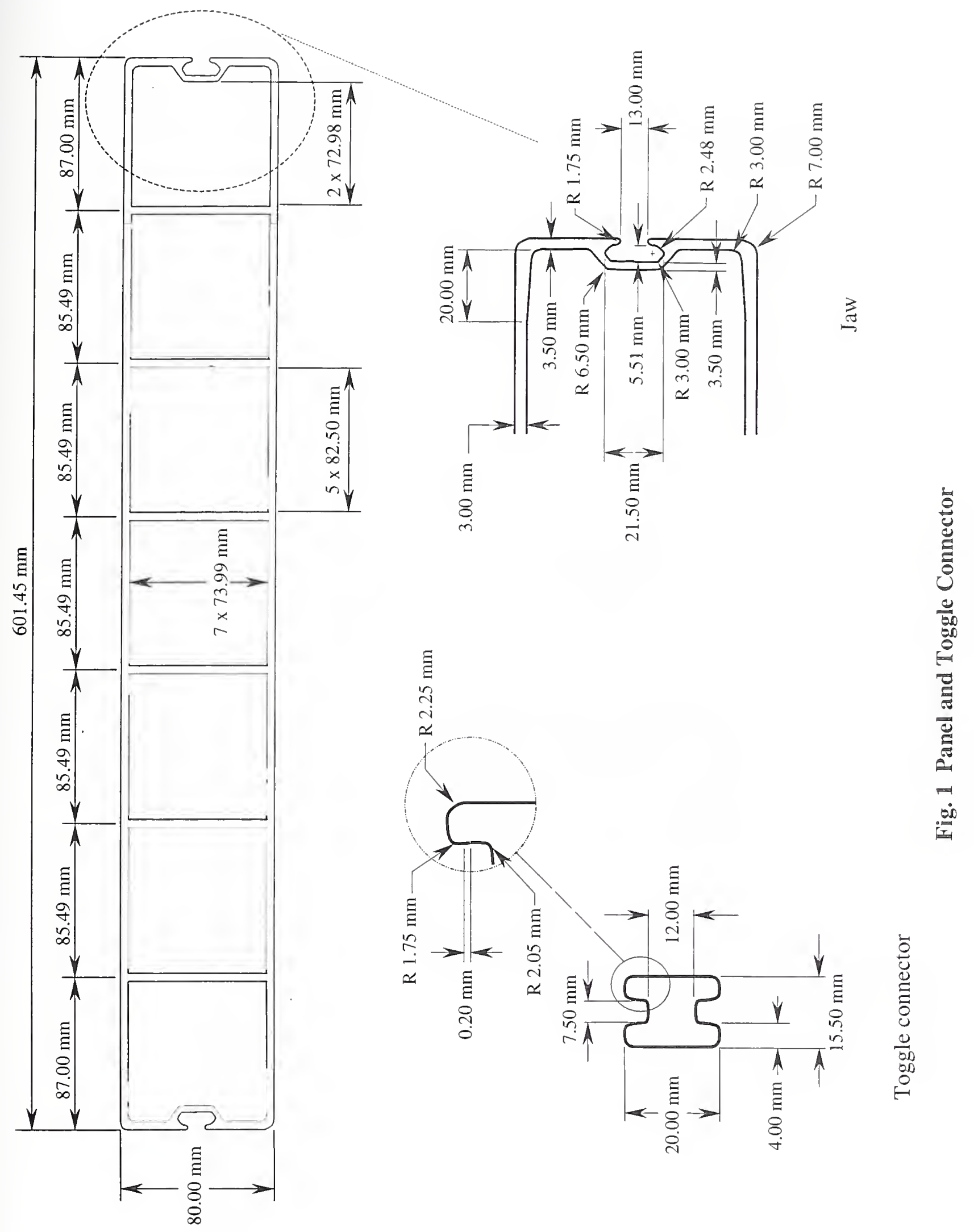



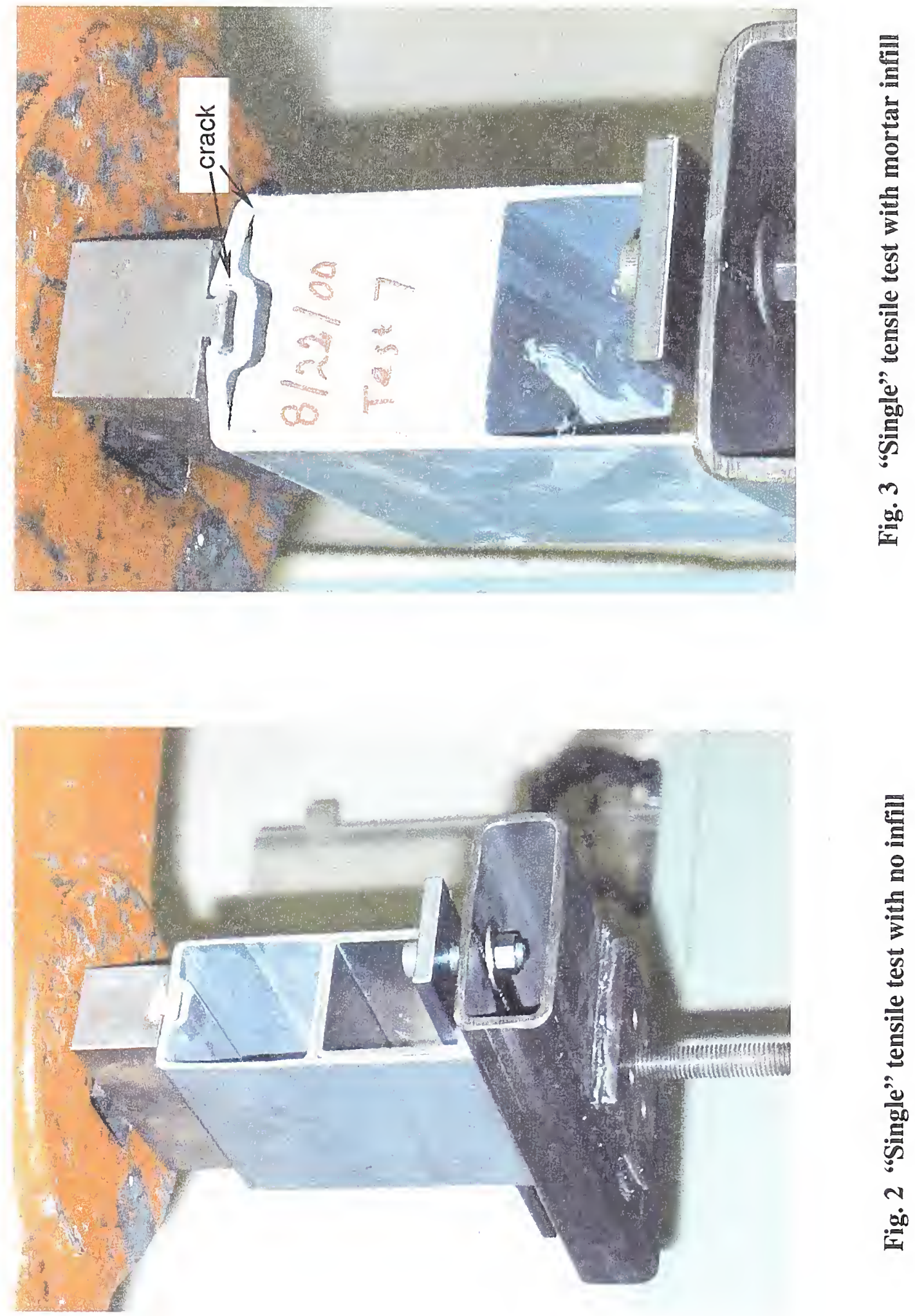

 


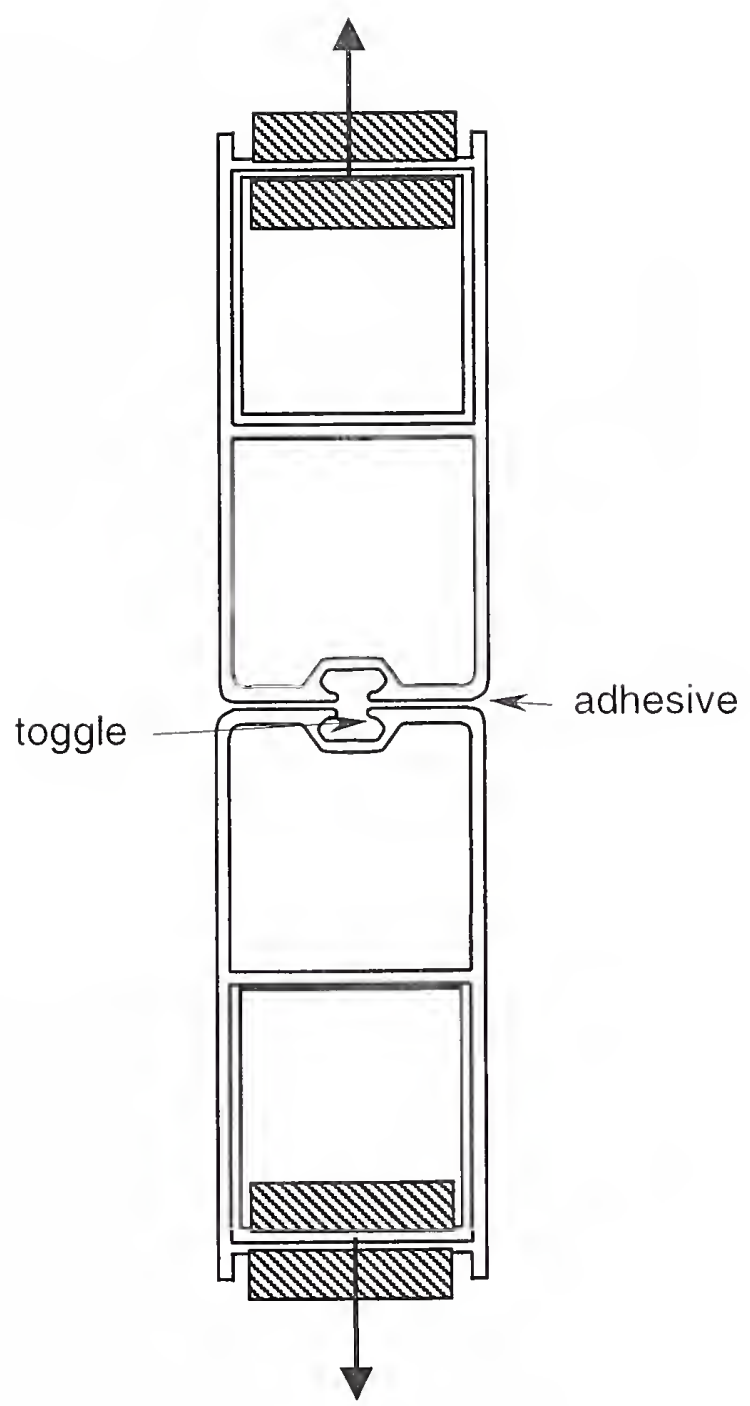

Fig. 4 "Double" test 

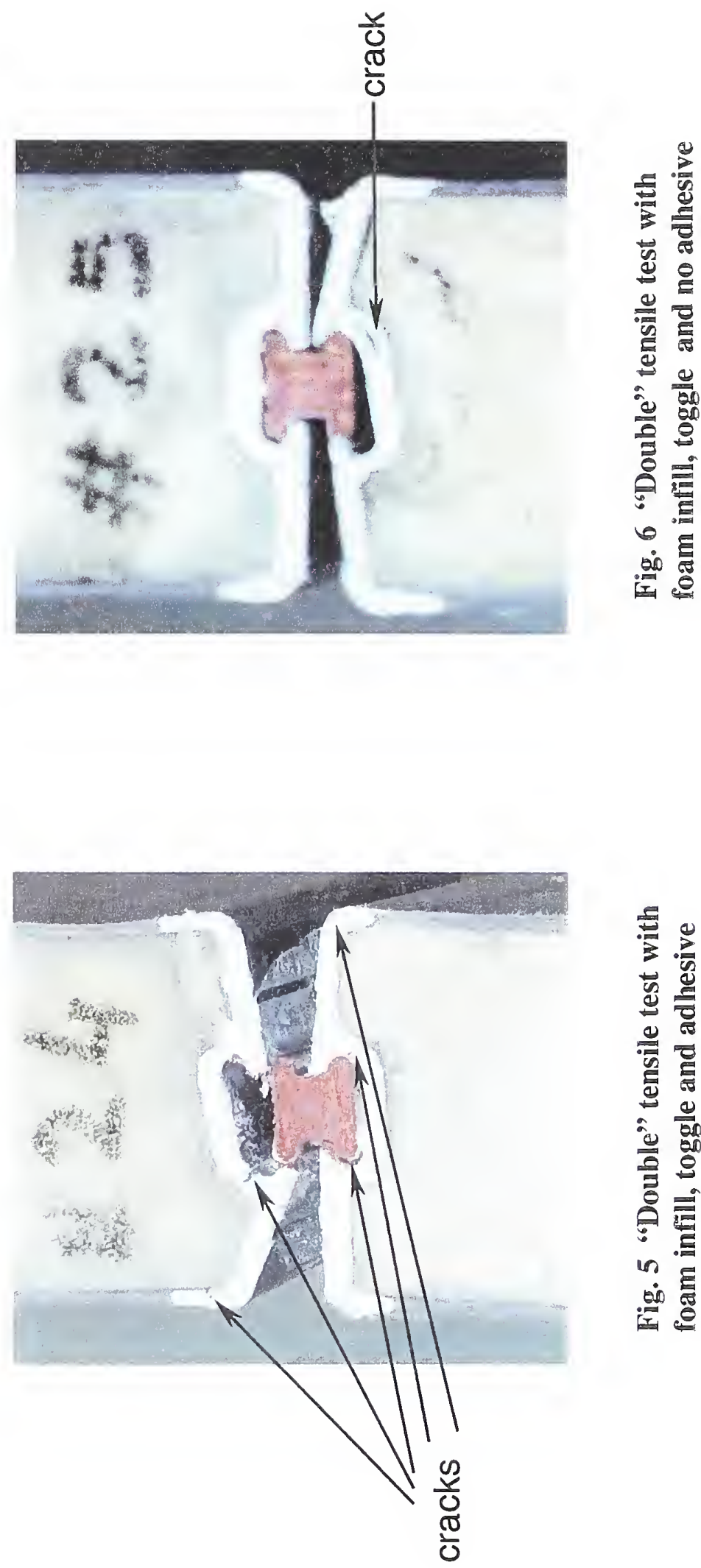

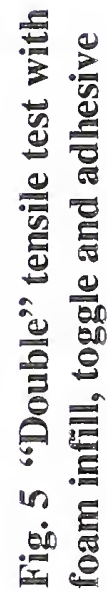




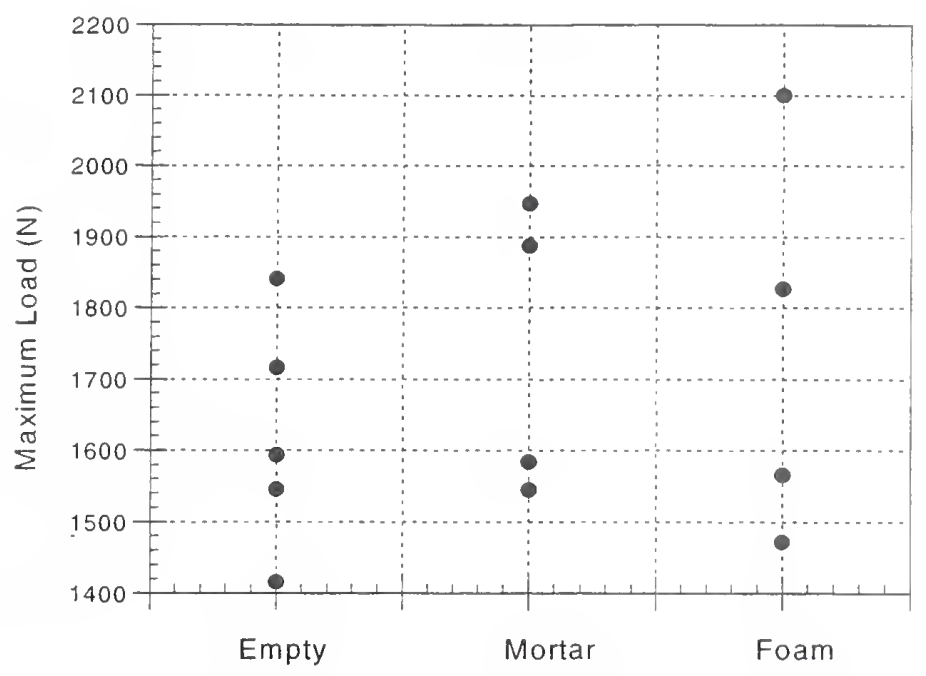

Summary statistics for maximum load for different infill material

\begin{tabular}{|l|l|l|l|l|}
\hline Group & Count & Mean $(\mathrm{N})$ & StdDev $(\mathrm{N})$ & StdErr $(\mathrm{N})$ \\
\hline Air or empty & 5 & 1622 & 163 & 73 \\
\hline Foam & 4 & 1741 & 283 & 141 \\
\hline Mortar & 4 & 1741 & 206 & 103 \\
\hline
\end{tabular}

ANOVA Table for effect of insert material on maximum load

\begin{tabular}{|l|l|l|l|l|l|}
\hline Source & df & Sums of Squares & Mean Square & F-ratio & Prob \\
\hline Const & 1 & $3.73663 \mathrm{e} 7$ & $3.73663 \mathrm{e} 7$ & 791.21 & $\leq 0.0001$ \\
\hline Infill & 2 & 43279.9 & 21639.9 & 0.45821 & 0.6451 \\
\hline Error & 10 & 472267 & 47226.7 & & \\
\hline Total & 12 & 515547 & & & \\
\hline
\end{tabular}

Fig. 7 Effect of infills on joint strength 


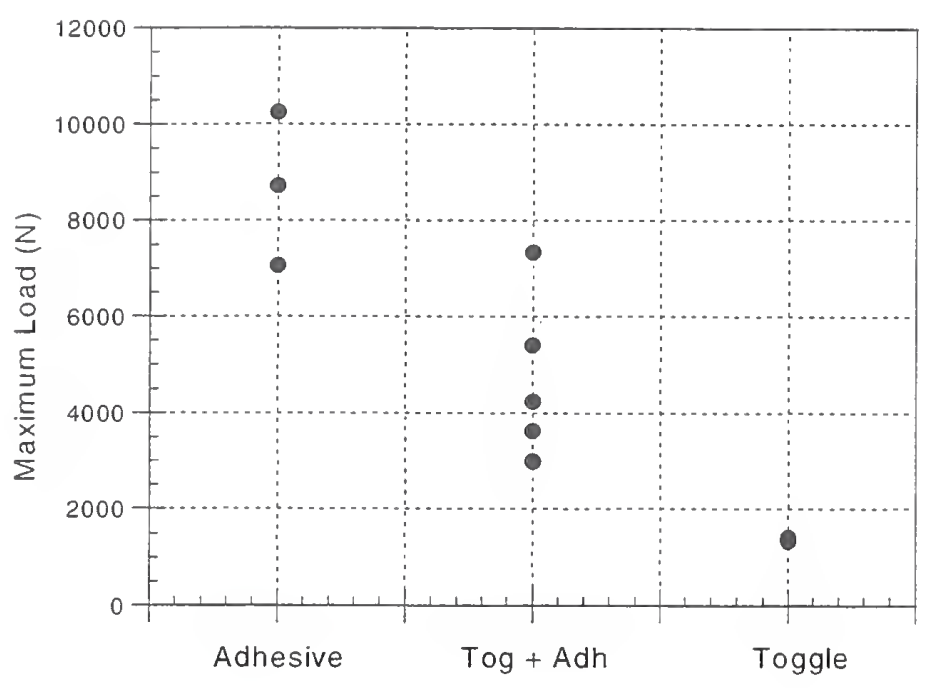

Summary statistics for maximum load for different joint conditions

\begin{tabular}{|l|l|l|l|l|}
\hline Group & Count & Mean $(\mathrm{N})$ & Std.Dev $(\mathrm{N})$ & StdErr $(\mathrm{N})$ \\
\hline Adhesive & 3 & 8682 & 1587 & 916 \\
\hline Tog+Adh & 5 & 4721 & 1717 & 768 \\
\hline Toggle & 3 & 1387 & 40 & 23 \\
\hline
\end{tabular}

ANOVA table for effect of type of joint

\begin{tabular}{|l|l|l|l|l|l|}
\hline Source & df & Sums of Squares & Mean Square & F-ratio & Prob \\
\hline Const & 1 & $2.63278 \mathrm{e} 8$ & $2.63278 \mathrm{e} 8$ & 125.13 & $\leq 0.0001$ \\
\hline Joint & 2 & $8.00938 \mathrm{e} 7$ & $4.00469 \mathrm{e} 7$ & 19.034 & 0.0009 \\
\hline Error & 8 & $1.68321 \mathrm{e} 7$ & $2.10402 \mathrm{e} 6$ & & \\
\hline Total & 10 & $9.69259 \mathrm{e} 7$ & & & \\
\hline
\end{tabular}

Ad-hoc test of differences of group means

\begin{tabular}{|l|l|l|l|}
\hline & Difference $(\mathrm{N})$ & Std. Err. $(\mathrm{N})$ & Prob \\
\hline Tog+Adh - Adhesive & -3961 & 1059 & 0.0175402 \\
\hline Toggle - Adhesive & -7295 & 1184 & 0.000919625 \\
\hline Toggle - Tog+Adh & -3334 & 1059 & 0.0398543 \\
\hline
\end{tabular}

Fig. 8 Effect of interlocking, bonding, or both on joint strength 

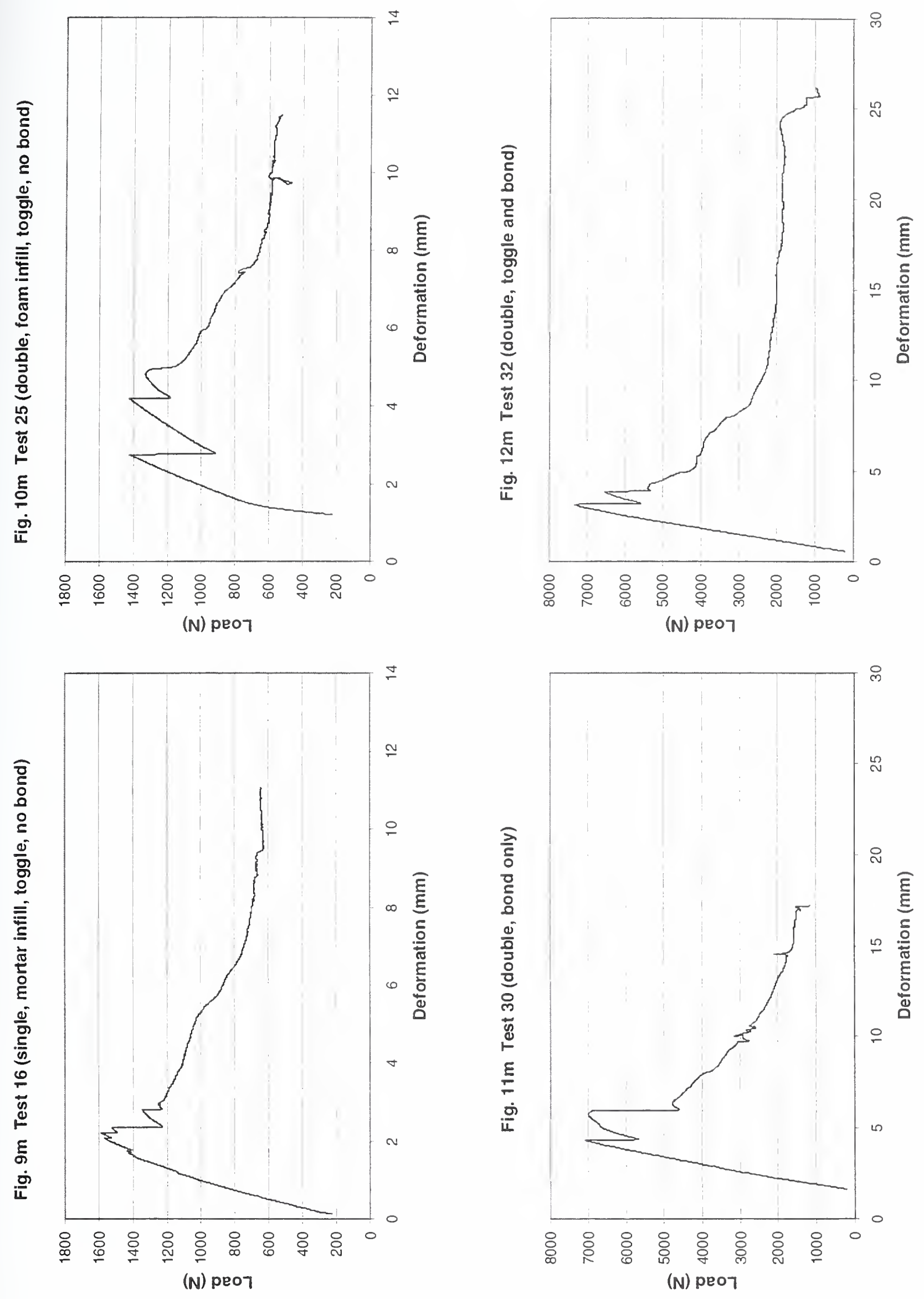


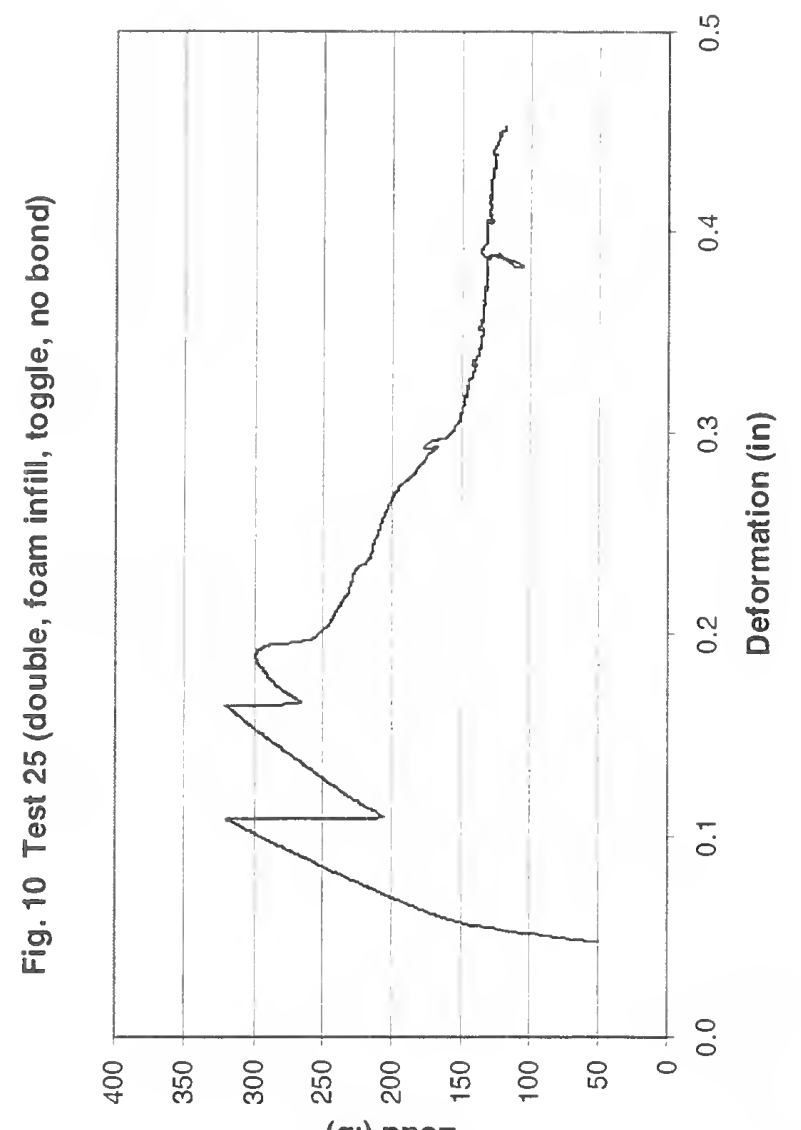

(qI) peo7

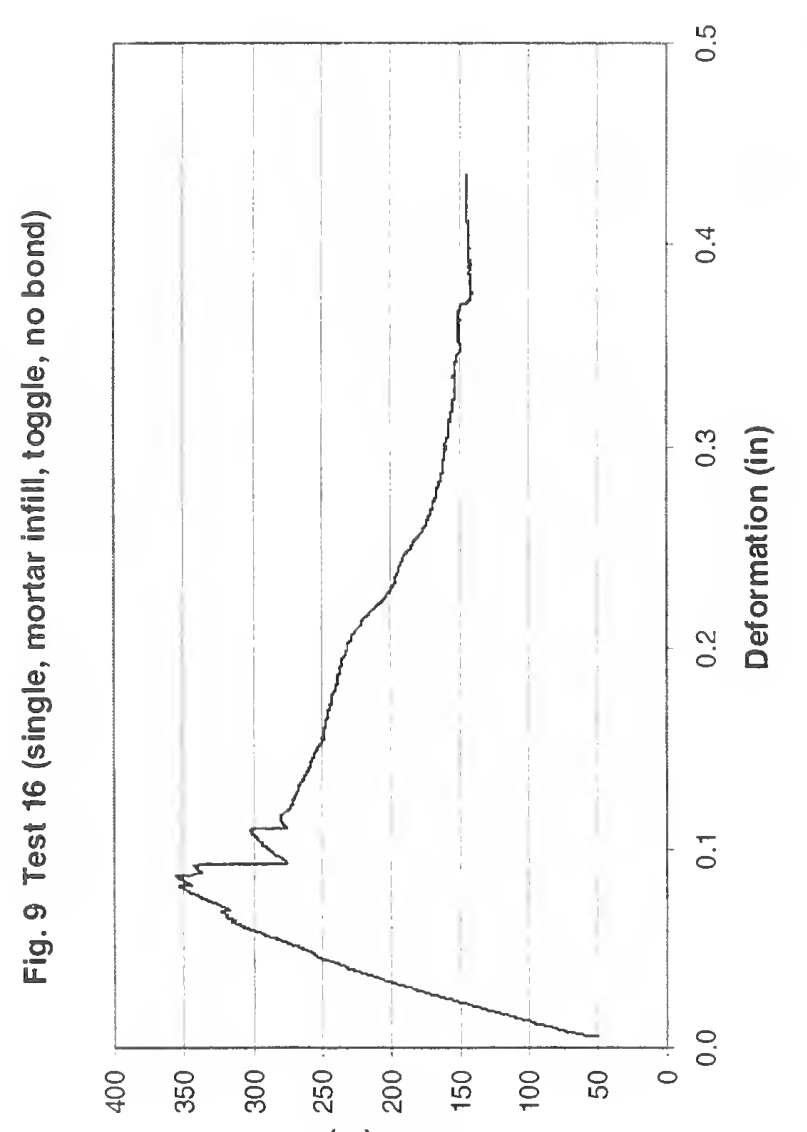

(q1) peo7
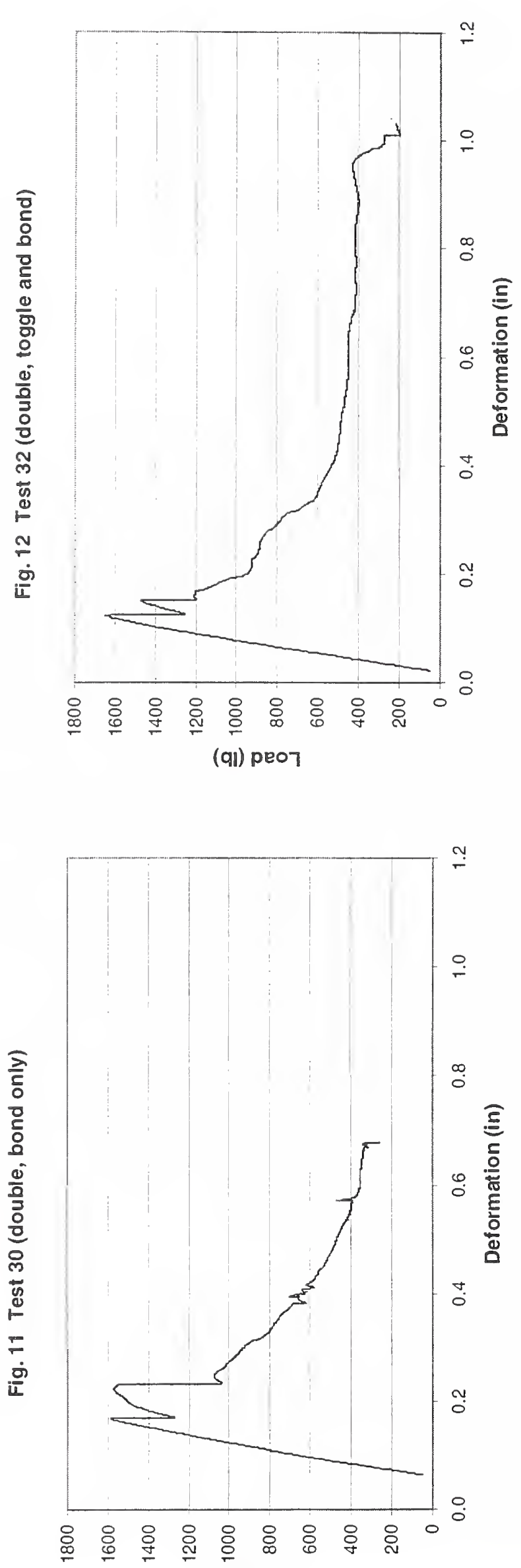

(qI) peo7 

